\title{
Long-Term Characteristics of Midlatitude Mesosphere Summer Echoes (MSE) Observed with a VHF Radar at Wakkanai, Japan $\left(45.4^{\circ} \mathrm{N}\right)$
}

\section{Tadahiko Ogawa ( $\sim$ taogawa@nict.go.jp)}

National Institute of Information and Communications Technology Keihanna Research Laboratories: Joho Tsushin Kenkyu Kiko Universal Communication Kenkyujo

\section{Hidehiko Suzuki}

Meiji University: Meiji Daigaku

\section{Nozomu Nishitani}

Nagoya University

\section{Yasuhiro Murayama}

National Institute of Information and Communications Technology Keihanna Research Laboratories: Joho Tsushin Kenkyu Kiko Universal Communication Kenkyujo

\section{Seiji Kawamura}

National Institute of Information and Communications Technology

\section{Full paper}

Keywords: (P)MSE, Midlatitude upper mesosphere, Ice particle, Noctilucent cloud (NLC), Polar mesospheric clouds (PMC), VHF radar, HF radar, MF radar

Posted Date: March 1st, 2021

DOl: https://doi.org/10.21203/rs.3.rs-249808/v1

License: (c) (1) This work is licensed under a Creative Commons Attribution 4.0 International License. Read Full License 


\section{Abstract}

Midlatitude mesosphere summer echoes (MSE) at the VHF band (VHF-MSE) were observed for 13 years (2000-2002 and 2009-2018) with a $46.5 \mathrm{MHz}$ radar at Wakkanai, Japan (45.4 $\left.{ }^{\circ} \mathrm{N}, 141.8^{\circ} \mathrm{E}\right)$. VHF-MSE are active during June-July and appear only in the daytime mainly at altitudes of 80-88 km with a maximum occurrence at $85 \mathrm{~km}$ and altitude extents of 1-4 km for a duration of about half an hour or more. The VHFMSE occurrences are positively correlated with solar activity, but not with geomagnetic activity except for very high activity. Such long-term characteristics are mostly consistent with past VHF-MSE observations at higher midlatitudes in Europe. No VHF-MSE were observed in 2002, 2014 and 2018, possible reasons for which are discussed. It is shown that cold ice particles in the upper mesosphere inducing MSE are advected from high latitudes to midlatitudes with equatorward wind. Thus, the MSE occurrences over Wakkanai are fundamentally controlled by both the solar activity and equatorward ice particle advection. One example of MSE at the HF band (HF-MSE) is presented to discuss spatial and temporal relationship between VHF-MSE and HF-MSE.

\section{Introduction}

Strong coherent radar echoes from the cold summer mesosphere at high latitudes are called polar mesosphere summer echoes (PMSE). PMSE, mainly appearing at 80-90 km altitudes, are caused by mesospheric neutral air turbulence and heavy charged ice aerosol particles (Rapp and Lübken 2004), and are mostly accompanied by noctilucent clouds (NLC) (e.g., Fiedler et al. 2017). PMSE have been mainly observed with VHF radars (hereafter called VHF-PMSE) at northern high latitudes (e.g., Ecklund and Balsley 1981; Rapp and Lübken 2004; Smirnova et al. 2010; Latteck and Bremer 2017).

VHF radar echoes similar to PMSE have been observed at higher midlatitudes (51-54 $\mathrm{N}$ ) in Germany (Czechowsky et al. 1979; Reid et al. 1989; Chilson et al. 1997; Latteck et al. 1999; Zecha et al. 2003) and the UK (Thomas et al. 1992; Thomas and Astin 1994; Thomas et al. 1996; Hooper and Thomas 1997), and also at $45.4^{\circ} \mathrm{N}$ in Japan (Ogawa et al. 2011), These midlatitude echoes are called mesosphere summer echoes (MSE). MSE observed with VHF radar are called VHF-MSE hereafter. VHF-MSE, appearing only during the daytime, exhibit rather rare occurrence and weak echo intensity. NLC at midlatitudes (Taylor et al. 2002; Wickwar et al. 2002; Suzuki et al. 2016) can be related to VHF-MSE, as will be discussed below. (P)MSE were also observed with HF radars at high latitudes (e.g., Karashtin et al. 1997; Kelley et al. 2002; Ogawa et al. 2002, 2004; Hosokawa et al. 2004, Ramos et al. 2009). and at midlatitude (Ogawa et al. 2013). MSE at the HF band are called HF-MSE hereafter.

As far as we know, long-term midlatitude MSE characteristics for periods over about 5 years have never been clarified until now. This paper discusses long-term occurrence characteristics of the midlatitude VHF-MSE for 13 years (2000-2002 and 2009-2018) observed with a VHF radar at Wakkanai in Hokkaido, Japan $\left(45.4^{\circ} \mathrm{N}, 141.8^{\circ} \mathrm{E} ; 36.6^{\circ} \mathrm{N}\right.$ geomagnetic). The geographical latitude of Wakkanai is lower by about 6-9 $9^{\circ}$ than the latitudes of the past VHF radar sites in Germany and the UK. Using long-term VHF-MSE data, we discuss MSE event days, solar and geomagnetic activity effects on MSE occurrences, echo 
occurrence time, echo altitudes, etc., and show that VHF-MSE appearing over Wakkanai only in the daytime are mainly controlled by both solar activity and amount of ice particles in the upper mesosphere that are advected southward from high latitudes with equatorward neutral wind. In addition, we present some typical examples of VHF-MSE and one example of HF-MSE to discuss spatial and temporal relationships between VHF-MSE and HF-MSE occurrence.

\section{Instrumentation}

We use data obtained with VHF, MF and HF radars in Hokkaido, Japan. The VHF (46.5 MHz, wavelength of $6.5 \mathrm{~m})$ and MF (1.96 MHz, wavelength of $153.1 \mathrm{~m}$ ) radars collocated at Wakkanai (Figure 1) observed MSE and horizontal neutral wind velocity, respectively, in the mesosphere over Wakkanai. See a paper by Ogawa et al. (2011) for the main technical parameters of both radars. In brief, the VHF radar equipped with 144 three-element Yagis has a peak power of $80 \mathrm{~kW}$, an antenna beam width of $6^{\circ}$ in the vertical, a time resolution of $3 \mathrm{~min}$, and a range resolution of $2 \mathrm{~km}$ in 2000 and $600 \mathrm{~m}$ after 2001. The collocated MF radar equipped with 4 crossed-dipole antennas has a peak power of $50 \mathrm{~kW}$, an antenna beam width of about $40^{\circ}$ in the vertical, a time resolution of 4 or 6 min depending on the year, and a range resolution of about $7 \mathrm{~km}$ (by oversampling in range, the sampling interval is set to $2 \mathrm{~km}$ ). Horizontal winds are derived by using the conventional full correlation analysis method. Both radars can observe echoes from a common volume over Wakkanai. Mesosphere observations with the VHF radar started on 7 July 2000, stopped once on 18 July 2002, and resumed on 10 June 2009. The MF radar observations started in September 1996. Both radars stopped operation in March 2019.

As shown in Fig. 1, two oblique-incidence HF radars, called "Hokkaido East (HOK)" and "Hokkaido West (HKW)" that belong to the Super Dual Auroral Radar Network (SuperDARN) (e.g., Nishitani et al. 2019), are located at Rikubetsu (43.5 $\mathrm{N}, 143.6^{\circ} \mathrm{E} ; 34.5^{\circ} \mathrm{N}$ geomagnetic), $260 \mathrm{~km}$ southeast of Wakkanai. HOK and HKW started operation in November 2006 and October 2014, respectively. Horizontal fields of view (FOVs) of HOK and HKW are shown in Fig. 1. Both HF radars can detect mesospheric and ionospheric echoes from a wide area at far ranges in the north of Hokkaido (Nishitani and Ogawa 2005). Each radar has 16 narrow horizontal beams (B0, B1, B2, ..., B15) over an azimuth sector of about $52^{\circ}$. We use a frequency of about $11.1 \mathrm{MHz}$ (wavelength of $27.1 \mathrm{~m}$ ) at which each beam has a two-way horizontal beam width of about $3.5^{\circ}$ and a maximum sensitivity at an elevation angle of about $30^{\circ}$ with a half power width of about $30^{\circ}$. In the observations, the beam is sequentially scanned from beam 15 to beam 0 with a scan repeat time of $60 \mathrm{~s}$. The range resolution and first range gate are $45 \mathrm{~km}$ and $180 \mathrm{~km}$, respectively. The solid curves in Fig. 1 indicate approximate slant ranges from the radar site at Rikubetsu (R). For mapping the slant ranges on the ground, we assume an echo altitude of $115 \mathrm{~km}$ for slant ranges of $150-600 \mathrm{~km}$ and higher than $150 \mathrm{~km}$ for slant ranges beyond $600 \mathrm{~km}$ (Chisham et al. 2008); therefore, if the echo altitude is $85 \mathrm{~km}$, the slant ranges should be mapped at farther positions (see below). As shown in Fig. 1, both HF radars can detect coherent echoes from near ranges due to field-aligned irregularities at 90-120 $\mathrm{km}$ altitudes in the ionospheric E-region (e.g., Ogawa et al. 2009). To observe these E-region echoes, the radar wave vector $(\mathbf{K})$ must be perpendicular to the geomagnetic field vector $(\mathrm{Bo})$ in the E-region, as shown in the figure. 


\section{VHF-MSE observations}

We picked up MSE events from the VHF radar data of signal-to-noise ratios (VHF-SNR) observed in MayAugust for 13 years (2000-2002 and 2009-2018). Each event satisfies all of the following three conditions: (1) echo altitudes between 75 and $90 \mathrm{~km}$, (2) echo duration beyond about $20 \mathrm{~min}$, (3) SNR above $-5 \mathrm{~dB}$. Echo events with durations less than 20 minutes and/or SNR lower than $-5 \mathrm{~dB}$ were omitted in the analysis because these echoes might be caused by radio interference, turbulence not related to MSE or others. As a result, we identified 110 events that appeared on 95 days in 10 years (2000-2001, 2009-2013 and 2015-2017), and no events in 2002, 2014 and 2018. These MSE occurred only in the daytime. Note that in this paper we use mainly Japan Standard Time (JST=UT+9 hours), instead of universal time (UT).

\section{Examples of VHF-MSE}

Examples of the altitude-time plot of VHF-SNR observed in June-July in each year in 2000-2001, 20092013 and 2015-2017 are shown in Figure 2. Two VHF-MSE events, separated by about 3 hours, were observed on 16 July 2000 and 16 June 2010. Two simultaneous MSE layers, separated by about $3 \mathrm{~km}$ in altitude, were observed during 0930-1000 JST on 17 July 2009. All MSE in Fig. 2 appear in the daytime between 0500 and $1700 \mathrm{JST}$ when the ionospheric D-region electron density is enhanced due to the solar radiation (see details below). Though the echo features are very different from event to event, MSE appear at altitudes of 76-89 km with altitude extents of 1-4 km for durations of 1-4 hours. The echo altitudes descend gradually with time $(0.3-0.8 \mathrm{~m} / \mathrm{s})$ for long hours, maybe due to atmospheric tides (e.g., Williams et al. 1995; Thomas et al. 1996; Chilson et al. 1997), while the altitudes do not change so much in some examples. Clearly, SNR are modulated mainly with periods of a few hours and also with those less than one hour, due to short-period atmospheric gravity waves (AGW).

The very strong geomagnetic storm, induced by the major solar proton event on 14 July 2000 , started on 15 July 2000 and lasted for a few days. The 3-hour geomagnetic Kp indices between 0900 UT (1800 JST) on 15 July and 0900 UT (1800 JST) on 16 July were between 4+ and 9, and the daily Ap index on 15 July and 16 July was 164 and 50 (see Figure 6), respectively. Rapp et al. (2002) and Barabash et al. (2004) observed VHF-PMSE associated with this storm, and discussed an effect of energetic particle precipitation on the PMSE formation (see also Rauf et al. 2018). Zecha et al. (2003) detected VHF-MSE at Kühlungsborn, Germany $\left(54.1^{\circ} \mathrm{N}, 11.8^{\circ} \mathrm{E}\right)$ on the night of $15 \mathrm{July}$. The Wakkanai VHF radar also detected daytime VHF-MSE on 15-17 July. When VHF-MSE were intermittently observed during 0730-1700 JST on 16 July, as shown in Fig. 2, the Kp indices (9-, 8-, 6 and 4+) were very high. We infer that these VHF-MSE might be initiated or affected by the highly-enhanced particle precipitation at northern latitudes higher than Wakkanai.

On 21 July 2001, Zeller et al. (2009) observed long-term (0300-1900 UT), strong PMSE above Andenes, Norway $\left(69.3^{\circ} \mathrm{N}, 16.0^{\circ} \mathrm{E}\right)$ and simultaneously midlatitude MSE during 1100-1900 UT (2000-0400 JST) around altitudes of $85 \mathrm{~km}$ above Kühlungsborn. The Wakkanai VHF-MSE occurrence around $1500 \mathrm{JST}$ 
(0600 UT) on 22 July 2001 shown in Fig. 2 may be related to these (P)MSE in the European sector, about $130^{\circ}$ west of Wakkanai.

Suzuki et al. (2016) reported the first imaging of NLC that appeared at altitudes around $84 \mathrm{~km}$ in the north of Hokkaido in the early morning (around 0200 JST) on 21 June 2015. As shown in Fig. 1, the NLC area $\left(47.5-50.0^{\circ} \mathrm{N}, 143.0-147.5^{\circ} \mathrm{E}\right)$ is covered with the HF HOK radar. The altitude-time plot of VHF-SNR on the same day (21 June 2015) is shown in Figure 3a where the MSE area surrounded by the solid rectangle appeared at altitudes of 83.5-87.0 km during 0900-1020 JST in the daytime. The echo altitudes decreased gradually at about $0.8 \mathrm{~m} / \mathrm{s}$. The MSE appeared with a delay of 7-8 hours from the NLC occurrence, suggesting that enough solar radiation was necessary to induce MSE. Figure $3 \mathrm{~b}$ shows horizontal wind vectors (averaged over $24 \mathrm{~min}$ ) observed on 21 June 2015 with the MF radar. When VHFMSE appeared during 0900-1200 JST, the winds (30-45 m/s) were clearly southward, suggesting that the ice particles and/or cold air causing MSE were advected from higher latitudes. Such kind of advection was also important for producing NLC in the north of Hokkaido observed by Suzuki et al. (2016). It is noted that HF-MSE associated with these VHF-MSE were not observed with the HF HOK and HKW radars.

Figures $3 \mathrm{c}$ and $3 \mathrm{~d}$, similar to Figs. 3a and 3b, show the VHF-MSE and wind data on 24 June 2015. In both figures, the time interval (0950-1040 JST) of the strong echoes observed with the HF HKW radar is indicated by the broken lines (see Fig. 10). In this example, though VHF-MSE are not so strong compared with those in Fig. 3a, the wind directions (40-50 m/s) are also southward during the MSE period.

\section{VHF-MSE for 13 years}

Figure 4 shows the VHF-MSE occurrence days during May-August in each year for 13 years (2000-2002 and 2009-2018). No mesospheric observations were made on the days marked by the grey rectangles. The number of the yearly occurrence days (0-19 days) varies from year to year. Unpredictable day-to-day variation in the MSE occurrences, maybe affected by the activity of planetary waves of a few to about 6 days, is discernible. Note no MSE days in 2002, 2014 and 2018 (the reasons are discussed below). The daily variation of the total MSE occurrence days (TMOD) for 13 years is shown in the bottom of Fig. 4 which indicates that MSE (95 days in total) appear between the middle of May and the beginning of August. Roughly speaking, TMOD increase gradually after 17 May, attains to a maximum (4 days) on 20 June around the summer solstice (21 June), and then gradually decreases to become zero in early August. Thus, MSE are active mainly during June-July.

To see a solar activity effect on the MSE occurrence, the right panel of Fig. 4 shows the long-term variations of the yearly MSE occurrence days (YMOD), yearly sunspot number (SSN) and solar Lyman Alpha radiation (Ly-a, $121.6 \mathrm{~nm}$ ). It is qualitatively clear that YMOD are high (low) for high (low) solar activity. To investigate the detailed correlations between YMOD and SSN and between YMOD and Ly-a, Figure 5 shows the scatter plots of YMOD versus (a) sunspot number (mean during June-July; JJSSN) and (b) Ly-a (mean during June-July; JJLYA) for 13 years. Except for no YMOD in 2002, 2014 and 2018, and very high YMOD in 2009, the correlations between YMOD and JJSSN and between YMOD and JJLYA are positive, as shown by the oblique solid lines. This fact indicates that YMOD are influenced by the 
solar radiation controlling the electron density in the upper mesosphere. Though JJSSN in 2002 and 2014 were high (144.9 and 101.6, respectively), MSE were not observed. JJSSN in 2009 was lowest (5.9), but YMOD was highest (19 days). The reasons of these facts are discussed below. JJSSN in 2018 was low (8.6), maybe resulting in no MSE.

As described above, high-energy particle precipitation into the high-latitude upper atmosphere associated with geomagnetic activity can increase the PMSE occurrence rate (Rapp et al. 2002; Barabash et al. 2004; Bremer et al. 2009; Zeller and Bremer 2009; Smirnova et al. 2010; Latteck and Bremer 2017). Here, we investigate this possibility for the Wakkanai MSE occurrences. For this purpose, using daily geomagnetic Ap indices during 20 May - 31 July (during which most of MSE were observed, as shown in Fig. 4), we obtained the total of Ap occurrence days (TAOD) at each Ap index for 10 years (2000-2001, 2009-2013 and 2015-2017); again, note no MSE occurrences in 2002, 20014 and 2018. Figure 6 shows a dependence of TAOD (solid lines) and TMOD (dotted lines) on the Ap index for 10 years. With increasing Ap index, TAOD increases rapidly from 1 at $A p=0$ to 105 at $A p=4$ and then monotonically decreases, while TMOD increases rapidly from 0 at $A p=0$ to 13 at $A p=6$ and then decreases as a whole (note that TMOD is 4 at $A p=20$ and mostly 0 beyond $A p=21$, and that the maximum Ap is 164 on 15 July 2000 when VHFMSE were observed, as described above). The TAOD variation is very similar to the TMOD one below $A p=20$, and TMOD does not increases with increasing Ap beyond about 20: Both facts indicate that in general, the MSE occurrences over Wakkanai are not almost controlled by the geomagnetic activity. It is noted, however, that VHF-MSE occurred on 8 days $(11,13,15,16$ and 20 July 2000, 17 June 2012, 1 June 2013 and 23 June 2015 when the solar activity was high, as shown in Fig. 5), when the strong geomagnetic activity with Ap higher than 30 happened.

\section{VHF-MSE occurrence time and altitudes}

Next, we investigate the statistical characteristics of the VHF-MSE occurrence time and altitudes. Figure $7 \mathrm{a}$ shows the time extent of each MSE event for 10 years (110 events in total). MSE appear rather sporadically in the daytime of 4-18 h JST (mainly during 7-17 h JST in 2000-2001 and during 5-14 $\mathrm{h}$ JST after 2009) with a maximum occurrence around 10-11 $\mathrm{h}$ JST before the noon (right panel). The histogram in Figure $7 \mathrm{~b}$ indicates that the MSE durations are mostly less than $4.5 \mathrm{~h}$ with a maximum occurrence at 0.5-1 h.

Figure 8a displays the altitude extent of each MSE event for 10 years (note a range resolution of $2 \mathrm{~km}$ in 2000 and $600 \mathrm{~m}$ in other years). The echo altitudes are between 76-90 km in 2000-2001 (high solar activity period), and between 81 and $89 \mathrm{~km}$ in 2009-2010 and 2016-2017 (low solar activity periods). These facts suggest the echo altitudes are affected by the solar activity. The histogram in the right panel shows that the echoes appear at 76-90 km with a maximum occurrence at around $85 \mathrm{~km}$. The histogram in Figure $8 \mathrm{~b}$ indicates that the echo altitude extents are mostly less than $8.5 \mathrm{~km}$ with a maximum occurrence at 2.5-3.5 km.

\section{No VHF-MSE in 2002, 2014, and 2018}


VHF-MSE were not observed in 2002, 2014 and 2018 (Fig. 4). Ogawa et al. (2011) noted that no occurrence in 2002 can be related to the enhanced mesopause temperature in the summer of this year. This temperature enhancement also affected the PMSE and MSE occurrences in 2002 at Andenes $\left(69.3^{\circ} \mathrm{N}\right)$ and Kühlungsborn $\left(54.1^{\circ} \mathrm{N}\right)$, respectively (Bremer et al. 2006; Zeller et al. 2009).

The Cloud Imaging and Particle Size (CIPS) instrument onboard the Aeronomy of Ice in the Mesosphere (AIM) satellite was launched by NASA in April 2007. AIM-CIPS can provide data of the ice water content of polar mesospheric clouds (PMC) in the full area at latitudes higher than about $70^{\circ}$ and in the partial areas at latitudes of $58-70^{\circ}$ from observations by the 15 satellite orbits per day (Russell et al. 2009; Thomas et al. 2019). The AIM-CIPS data are useful to study the PMC activity which is closely related to the PMSE occurrence (e.g., Rapp and Lübken 2004).

We analyzed the AIM-CIPS data, "V5.20r05 (version v5.20, revision 05)", to know a relationship between Wakkanai VHF-MSE occurrence and PMC activity at high latitudes in the north of Wakkanai. It is noted that no CIPS data are available over Wakkanai $\left(45.4^{\circ} \mathrm{N}\right)$. The CIPS data provide cloud frequency (CF) which is defined as a ratio of number of pixels in bin containing clouds to total number of data points in bin: Thus, the CF data give information on the amount of mesospheric ice particles. Figure 9a shows the daily variations of (upper) CFs during 9 years of 2009-2016 and 2018 (no CIPS data in 2017), averaged over both $58-70^{\circ} \mathrm{N}$ (about $13-25^{\circ}$ north of Wakkanai) and 0-360 $\mathrm{E}$, and of (lower) TMOD on each day during 2009-2018 (Fig. 4). The daily and yearly variations of CFs are very large and complex. As indicated by the thick line (CFs averaged over 9 years), CFs start to increase around the end of May, attains to a maximum around 3 July, and subsides around the middle of August. Corresponding to the enhanced CFs, TMOD starts to increase after 26 May, attains to a maximum (TMOD $=4$ days) on 20 June and decreases gradually toward zero. After 20 July, TMOD is almost zero irrespective of the high CF values, suggesting that the ice particles at high latitudes could not arrive over Wakkanai, resulting in no MSE occurrences. Before 20 July the ice particles arrived above Wakkanai to cause MSE. Figure 9b shows the daily variations of (upper) CFs in 2009 and 2012 shown in Fig. 9a and (lower) TMOD in these years (Fig. 4). In these years CFs are, as a whole, higher than the 9-year average CFs (thick line), resulting in the high TMOD (19 and 12 days, respectively). Figure 9c shows the daily variations of CFs in 2014 and 2018 in which CFs are, as a whole, lower than the 9-year average CFs, resulting in no MSE. Thus, Fig. 9 indicates that the MSE occurrences over Wakkanai are controlled in general by the amount of the ice particles at high latitudes and also by the southward advection of the particles from high latitudes.

\section{HF-MSE observation}

If VHF and HF radar scatterers (plasma turbulence and/or electron density structure) are isotropic (not aspect sensitive), MSE can be detected with both vertical-incidence VHF and oblique-incidence HF radar. On the contrary, if these are highly anisotropic (highly aspect sensitive), MSE cannot be detected with an oblique-incidence HF radar: This may be one of the reasons why HF-MSE have been rarely observed with the HOK HF radar, equipped with an antenna beam with an elevation angle of about $30^{\circ}$, at Rikubetsu 
(Ogawa et al. 2013). See Rapp and Lübken (2004) for discussion about the aspect sensitivity (i.e., signal dependence on radar beam tilted from the vertical direction) of VHF-PMSE.

Figure 10 shows HF-MSE that appeared before the VHF-MSE occurrence on 24 June 2015 (Figs. 3c and 3d). MSE were detected with HKW but not with HOK. The echo intensity and Doppler velocity on beams of B9, B11, B13 and B15 of HKW are shown in Figures 10a and 10b, respectively. The radar frequency was between 11.0-11.1 MHz (wavelength of about $27 \mathrm{~m}$ ). In Fig. 10a, the strong echo region (SNR $\geq 40 \mathrm{~dB}$ ) moves toward the lower beam numbers (i.e., from B15 to B9) with time, indicating a southward or southwestward movement of the echo region. This movement is consistent with the positive Doppler velocities shown in Fig. 10b: Note that Doppler velocity is positive (negative) for motion toward (away from) the radar site. The Doppler velocities of about $+40 \mathrm{~m} / \mathrm{s}$ are consistent with the southward wind velocities observed with the MF radar (Fig. 3d). It is noted that the spectral widths of the HF echoes are narrow and less than about $15 \mathrm{~m} / \mathrm{s}$ (not shown).

Figure 10c shows the two-dimensional maps of the Doppler velocity at three times (1010, 1018 and 1026 JST) observed with both HOK and HKW. The extended HF-MSE region with high positive velocities exists in these maps in HKW. This region is limited only within slant ranges of about 200-500 km, mainly because of the antenna beam pattern in the vertical: As stated above, HKW (also HOK) has a maximum sensitivity at an elevation angle of about $30^{\circ}$ with a half power width of about $30^{\circ}$. The isolated strong MSE region, appearing only on the HKW maps, moved southward at about $40 \mathrm{~m} / \mathrm{s}$. These HF-MSE are surely related to the VHF-MSE over Wakkanai that started around 1100 JST (Fig. 3c). In Fig. 10c, the southernmost HF-MSE region at three times before 1026 JST is very close to Wakkanai. However, this not always the case. In order to construct the echo maps shown in Fig.4c, we assume an echo altitude of 115 $\mathrm{km}$ for slant ranges of 150-600 km (see above); therefore, for an echo altitude of $85 \mathrm{~km}$ (for the VHF-MSE case, see above), the real echo region should be mapped at farther ground ranges. In fact, as shown in Fig. 3c, about 20 minutes or more were necessary for the HF-MSE region to arrive over Wakkanai. HF-MSE similar to those in Fig. 10 were observed with HOK in June 2009 (Ogawa et al. 2013). It is noted that each $\mathrm{HF}$ radar has a wide beam width of about $30^{\circ}$ and about $3.5^{\circ}$ in the vertical and horizontal planes, respectively, and a coarse range resolution $(45 \mathrm{~km})$, making it difficult to know exact echo altitudes and horizontal extent.

If these HF-MSE are coherent echoes due to ionospheric E-region irregularities at altitudes of 90-120 km, the echoes should appear only in the area indicated in Figs. 1 and 10c (Ogawa et al. 2009). Though a routine ionosonde at Sarobetsu in Hokkaido $\left(45.16^{\circ} \mathrm{N}, 141.75^{\circ} \mathrm{E}\right.$; about $30 \mathrm{~km}$ south of Wakkanai) observed foEs of 7-8 $\mathrm{MHz}$ during the period shown in Fig. 10c. no appreciable E region echoes were detected with the HF radars.

\section{Summary And Discussion}

In order to clarify the long-term characteristics of midlatitude $\left(45.4^{\circ} \mathrm{N}\right) \mathrm{MSE}$, we have investigated the Wakkanai VHF-MSE events for 13 years (2000-2002 and 2009-2018), and picked up 110 events on 95 
days in 10 years (2000-2001, 2009-2013 and 2015-2017). No VHF-MSE appeared in 3 years (2002, 2014 and 2018). The main results are summarized as follows:

1. Some of the MSE examples shown in Fig. 2 indicate that the echo altitudes descend gradually with time $(0.3-0.8 \mathrm{~m} / \mathrm{s})$ for long hours, maybe due to atmospheric tides. SNR are modulated mainly with periods of a few hours and also with those less than one hour, due to short-period AGW. Such MSE characteristics are similar to those obtained from higher midlatitude observations in Germany $\left(51.7^{\circ} \mathrm{N}, 54.1^{\circ} \mathrm{N}\right)\left(\right.$ Chilson et al. 1997; Zecha et al. 2003) and the UK $\left(52.4^{\circ} \mathrm{N}\right)($ Thomas et al. 1992; Thomas and Astin 1994; Thomas et al. 1996; Hooper and Thomas 1997).

2. The common volume observations of MSE and neutral winds (Fig. 3) indicate that the equatorward mesospheric wind transports cold ice particles and plasma turbulence from higher latitudes to cause MSE over Wakkanai (e.g., Gerding et al. 2007, Zeller et al. 2009; Morris et al. 2007, 2009). Such southward transport of the ice particles is supported by the analysis of the AIM-CIPS data (Fig. 9). For the MSE occurrences, for examples, Singer et al. (2003) pointed out a role of equatorwarddirected mean winds in transporting cold air from higher to lower latitudes, and Gerding et al. (2007) concluded that NLC over Kühlungsborn $\left(54.1^{\circ} \mathrm{N}\right)$ were strongly coupled to the advection of ice particles from northern higher latitudes. Such kind of the advection was also important for producing NLC observed on 21 June 2015 in the north of Hokkaido (Suzuki et al. 2016).

3. As shown in Fig. 4, the VHF-MSE season starts around the middle of May and ends in early August with high activity around the summer solstice. MSE are active mainly during June-July, in line with the result of Zecha et al. (2003) who made the VHF radar observations at Kühlungsborn in 1998, 2000 and 2001 to find that the mean starting and last days of MSE events at 78.5-92 km were 3 June and 14 August, respectively (see also Bremer et al. 2006, 2009). Similar characteristics of VHFPMSE were observed by Hoffman et al. (1999): They showed, from the observations at Andenes in Norway $\left(69.3^{\circ} \mathrm{N}\right)$ during four summer seasons in 1994-1997, that the PMSE occurrences were characterized by steep increase in late May/early June, maximum at some days after the summer solstice and slow decrease starting during the last decade of July: See also Latteck and Bremer $2013,2017)$ for the long-term VHF-PMSE occurrence characteristics at Andenes.

4. Except for no YMOD in 2002, 2014 and 2018 and very high YMOD in 2009, the correlation between YMOD and JJSSN (also Ly-a) is positive (Fig. 5), indicating that VHF-MSE are affected by the solar radiation controlling the electron density in the daytime upper mesosphere. The positive correlation between the solar activity and (P)MSE occurrence rate was well discussed by e.g., Bremer et al. (2001, 2009), Smirnova et al. (2010), Li and Rapp (2011) and Latteck and Bremer (2017). Using longterm PMSE data for 21 years (1994-1997, 1999-2008 and 2010-2016) at Andøya in Norway $\left(69.3^{\circ} \mathrm{N}\right)$, Latteck and Bremer (2017) discussed the dependences of PMSE on the solar and geomagnetic activities, and found that the PMSE occurrence rate was positively correlated with Ly-a radiation (however, low significance level) and with geomagnetic Ap index. In our case, the MSE occurrences over Wakkanai $\left(36.6^{\circ} \mathrm{N}\right.$ geomagnetic) are not correlated with the geomagnetic activity for Ap lower than about 20, suggesting that high-energy particle precipitation at high latitudes does not directly affect the midlatitude MSE. It is noted that MSE over Wakkanai appeared on the high geomagnetic 
activity days ( 8 days in 2000, 2012 and 2015) with Ap higher than 30 during the high solar activity (Fig. 6).

5. As shown in Fig. 5, the VHF-MSE occurrences are frequent in 2009 and 2012. In particular, YMOD (9 days) in July 2009 is very high in spite of the low solar activity. Nielsen et al. (2011) discussed the reason of the very frequent NLC occurrences at midlatitudes in July 2009. Also, Russell et al. (2014) noted that the number of the midlatitude NLC occurrences in 2009 was significantly larger, and that in mid-June 2012, NLC were observed in Spain (37.2 N). Suzuki et al. (2016) pointed out the great enhancement of NLC occurrences at midlatitudes in July 2009 in which NLCs were sighted in e.g., Colorado $\left(39^{\circ} \mathrm{N}\right)$ and Virginia $\left(38^{\circ} \mathrm{N}\right)$ in USA and in many European countries. Thus, the VHF-MSE occurrences over Wakkanai in 2009 are surely related to the very frequent NLC occurrences at midlatitudes and also at high latitudes (Fig. 9b).

6. As shown in Fig. 7, MSE appear rather sporadically in the daytime (mainly during 5-15 $\mathrm{h}$ JST with a maximum around $10-11 \mathrm{~h} \mathrm{JST}$ ). The MSE durations are mostly less than $4.5 \mathrm{~h}$ with a maximum at 0.5-1 h.

7. Fig. 8 a indicates that MSE appear mainly at altitudes of $80-88 \mathrm{~km}$ with a maximum at about $85 \mathrm{~km}$ (note again a range resolution of $2 \mathrm{~km}$ in 2000 and $600 \mathrm{~m}$ in other years). Similar results were presented by Reid et al. (1989) who made VHF-MSE observations at the Harz mountains of Germany $\left(51.7^{\circ} \mathrm{N}, 10.5^{\circ} \mathrm{E}\right)$. Using 21 years data, Latteck and Bremer (2017) presented that PMSE appeared at 79-92 km altitudes with a maximum occurrence around $85 \mathrm{~km}$, being consistent with our result; see also e.g., Ecklund and Balsley (1981) and Rapp and Lübken (2004). In Fig. 8a, the echo altitudes are between 76-90 km in 2000-2001 (high solar activity period), and between 81 and $89 \mathrm{~km}$ in 2009-2010 and 2016-2017 (low solar activity periods). These facts suggest the echo altitudes are affected by the solar activity. Fig. $8 \mathrm{~b}$ shows that the MSE altitude extents are mostly less than $8.5 \mathrm{~km}$ with a maximum occurrence at 2.5-3.5 km.

8. VHF-MSE were not observed in 2002, 2014 (high SSN in both years) and 2018 (low SSN). As discussed by Ogawa et al. (2011), no MSE in 2002 can be related to the enhanced summer mesopause temperature at northern high latitudes due to high planetary Rossby-wave activity in the southern hemisphere. Bremer et al. (2006) showed that the VHF-MSE occurrence rates at Kühlungsborn were lower in 2002 by about $10-20 \%$ than in 2000-2001, and also noted that the VHFPMSE occurrences at Andenes were unusually low in 2002 because of the enhanced mesopause temperature (see also Zeller et al. 2009). As shown in Fig. 9c, the AIM-CIPS CF values in June-July 2014 and 2018 were low, which is the reason for no MSE occurrences over Wakkanai in both years, while as shown in Fig.9b, those in 2009 and 2012 were largely enhanced to result in the high MSE activity (YMOD=19 and 12 days, respectively). These facts suggest that the MSE occurrences over Wakkanai are controlled by the amount of ice particles advected from high latitudes. Note that no MSE days in 2018 may be also related to the very low solar activity (Fig. 5). Thus, the MSE occurrences are controlled by the solar radiation, ice particle production (CF) at high-latitudes and ice particle advection to the equator. 
9. There have been few opportunities of observing MSE with the oblique-incidence HF radars at Rikubetsu. Using the HOK radar, Ogawa et al. (2013) found, for the first time, three HF-MSE events (two of which were accompanied with simultaneous VHF-MSE) appeared in June 2009 (in this year, the midlatitude NLC occurrences were significantly large, as stated above) in the north of Hokkaido, and clarified the echo characteristics. One additional example observed with the HKW radar is shown in Fig. 10 where the HF-MSE area moved southward at about $40 \mathrm{~m} / \mathrm{s}$ to induce the VHF-MSE over Wakkanai (Fig. 3c). The observed HF-MSE ranges are less than about 500 km: This is mainly because of the limited beam pattern in the vertical (maximum sensitivity at an elevation angle of about $30^{\circ}$ with a half power width of about $30^{\circ}$ ), so that it is difficult to detect directly echoes with low elevation angles from far ranges beyond about $500 \mathrm{~km}$. Fig. 10c indicates that the HF-MSE area is not so extensive in the east-west direction, resulting in the MSE detection only by HKW. Such HFMSE features are consistent with those reported by Ogawa et al. (2013). In the future it is necessary to investigate more detailed characteristics and production mechanisms of HF-MSE observed by an oblique-incidence HF radar.

\section{Conclusion}

The VHF-MSE events observed with the Wakkanai VHF radar for 13 years (2000-2002 and 2009-2018) have been analyzed. The number of MSE occurrence days are 95 days in total. The occurrences are positively correlated with the solar activity (SSN and Ly-a), but not with the geomagnetic activity for Ap below about 20 . When the geomagnetic activity was high (Ap above about 30), MSE appeared often.

No MSE events were observed in 2002, 2014 and 2018, the reasons for which are as follows:

- In 2002, the mesopause temperature at northern high latitudes in summer was higher because of high planetary wave activity at southern high latitudes.

- In 2014 and 2018, the ice particles advected equatorward from high latitudes were fewer than those in other years. Additionally, the solar activity in 2018 was very low, resulting in possible low electron density in the upper atmosphere.

The VHF-MSE occurrence days in 2009 are large (19 days) in spite of the low solar activity, the reason for which may be plentiful ice particle transport from higher latitudes, as supported by the AIM-CIPS CF data shown in Fig. 9b. The MSE occurrences over Wakkanai are controlled by both the solar radiation and the equatorward ice particle advection.

MSE are active mainly during June-July, and appear only in the daytime with a maximum occurrence around 10-11 h JST before noon and mainly at altitudes of 80-88 km (with a maximum occurrence at 85 $\mathrm{km}$ ) with altitude extents of 1-4 km for a duration of about half an hour or more. The echo altitudes descend gradually with time $(0.3-0.8 \mathrm{~m} / \mathrm{s})$ for long hours, maybe due to atmospheric tides, These characteristics are consistent with the past MSE observations at higher midlatitudes (Harz mountains of

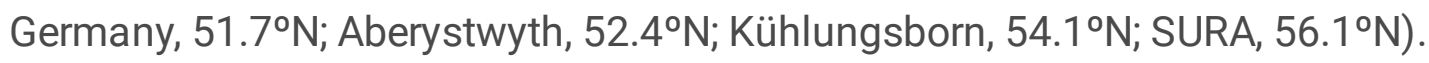


The AIM-CIPS CF data indicate that ice particles in the upper mesosphere causing MSE are advected from high latitudes with equatorward winds. These winds were observed with the MF radar and also caused southward movement of the HF-MSE area, as exemplified in this paper.

The long-term characteristics of VHF-MSE over Wakkanai clarified in this paper are similar to those at the observation stations in Germany and the UK. These facts indicate that the Wakkanai VHF-MSE are caused by the mechanisms similar to those working in the summer mesopause region over higher midlatitude European stations. The detailed analyses demonstrate that the Wakkanai VHF-MSE can be related to the advection of cold ice particles from northern high latitudes, in line with previous observations in Germany. One finding from our long-term observations is that VHF-MSE are rarely accompanied by simultaneous HF-MSE

\section{Abbreviations}

AGW: atmospheric gravity waves, AIM: Aeronomy of Ice in the Mesosphere, Ap index: daily geomagnetic activity index, CF: cloud frequency, CIPS: Cloud Imaging and Particle Size; FOV: field of view, HF: highfrequency, HOK (HKW): SuperDARN Hokkaido east (west) radar, JJLYA: mean value of Ly-a during JuneJuly, JJSSN: mean value of SSN during June-July, JST: Japan Standard Time, Ly-a: Lyman alpha, MF: middle frequency, NLC: noctilucent cloud, NASA: National Aeronautics and Space Administration, PMC: polar mesospheric cloud, (P)MSE: (polar) mesosphere summer echoes, SNR: signal-to-noise ratio, SSN: sunspot number, SuperDARN: Super Dual Auroral Radar Network, TAOD: total Ap occurrence days, TMOD: total MSE occurrence days, VHF: very high-frequency, VHF(HF)-MSE: mesosphere summer echoes at VHF(HF), VHF-PMSE: polar mesosphere summer echoes at VHF, VHF (HF)-SNR: signal-to-noise ratio at VHF (HF), YMOD: yearly MSE occurrence days

\section{Declarations}

\section{Acknowledgements}

We wish to thank Fusako Isoda for helping analysis of the Wakkanai VHF radar data. The Wakkanai VHF and MF radars belonged to and were operated by the National Institute of Information and Communications Technology. The SuperDARN HF radars at Rikubetsu belong to and are operated by the Institute for Space-Earth Environmental Research, Nagoya University.

\section{Authors' contributions}

TO analyzed the VHF, MF and HF radar data. HS analyzed the AIM-CIPS CF data. NN operated the HOK and HKW HF radars. YM and SK operated the VHF and MF radars. All authors contributed to the preparation of this manuscript and read and approved the final manuscript.

\section{Funding}


The work of HS is supported by the Japan Society for the Promotion of Science (JSPS) KAKENHI Grant Number JP19H01956. The work of NN is supported by the JSPS KAKENHI Grant Number 16H06286, 18KK0099, 19 K03949.

\section{Availability of data and materials}

The Wakkanai VHF and MF radar data used in this paper are available upon request to the corresponding author SH (s-kawamura@nict.go.jp). The SuperDARN Hokkaido East and West radar data are available from the Virginia Tech SuperDARN website (vt.superdarn.org). The AIM-CIPS data are provided through http://lasp.colorado.edu/aim/index.php. The geomagnetic index data were obtained through http://wdc.kugi.kyoto-u.ac.jp/wdc/Sec1-j.html. The sunspot number and solar Lyman Alpha radiation data were obtained through sidc.oma.be/silso/ and http://lasp.colorado.edu/lisird/lya/, respectively.

\section{Ethics approval and consent to participate}

Not applicable

\section{Consent for publication}

Not applicable

\section{Competing interests}

The authors declare that they have no competing interests.

\section{Author details}

${ }^{1}$ National Institute of Information and Communications Technology, Koganei, Tokyo 184-8795, Japan.

${ }^{2}$ Meiji University, Tama, Kawasaki, Kanagawa 214-8571, Japan. ${ }^{3}$ Institute for Space-Earth Environmental Research, Nagoya University, Chikusa, Nagoya 464-8601, Japan

\section{References}

Barabash V, Kirkwood S, Feofilov A, Kutepov A (2004) Polar mesosphere summer echoes during the July 2000 solar proton event. Ann Geophys 22:759-771.

Bremer J, Hansen TL, Hoffmann P, Latteck R (2001) Dependence of polar mesosphere summer echoes on solar and geomagnetic activity. Adv Space Res 28:1071-1076.

Bremer J, Hoffmann P, Höffner J, Latteck R, Singer W, Zecha M, Zeller O (2006) Long-term changes of mesospheric summer echoes at polar and middle latitudes. J Atmos Sol Terr 
Phys 68:1940-1951.

Bremer J, Hoffman P, Latteck R, Singer W, Zecha M (2009) Long-term changes of (polar) mesospheric summer echoes. J Atmos Sol Terr Phys 71:4571-4576.

Chilson, PB, Czechowsky P, Klostermeyer J., Rüster R., Schmidt G (1997) An investigation of measured temperature profiles and VHF mesosphere summer echoes at midlatitudes. $\mathrm{J}$ Geophys Res 102(D20):23,819-23,828.

Chisham G, Yeoman TK, Sofko GJ (2008) Mapping ionospheric backscatter measured by the SuperDARN HF radars - Par 1: A new empirical virtual height model. Ann Geophys 26:823-841.

Czechowsky P, Rüster R, Schmidt G (1979) Variations of mesospheric structures in different seasons. Geophys Res Lett 6(6):459-462.

Ecklund WL, Balsley BB (1981) Long-term observations of the arctic mesosphere with the MST radar at Poker Flat, Alaska. J Geophys Res 86(A9):7775-7780.

Fiedler J, Baumgarten G, Berger U, Lübken FJ (2017) Long-term variations of noctilucent clouds at ALOMAR. J Atmos Sol Terr Phys 162:79-89.

Gerding M, Höffner J, Rauthe M, Singer W. Zecha M, Lübken FJ (2007) Simultaneous observation of noctilucent clouds, mesospheric summer echoes, and temperature at a midlatitude station (54N). J Geophys Res 112:D12111.

Hoffman P, Singer W, Bremer J (1999) Mean seasonal and diurnal variations of PMSE and winds from 4 years of radar observations at ALOMAR. Geophys Res Lett 26:1525-1528.

Hooper DA, Thomas J (1997) The small-scale structure of VHF mesospheric summer echo layers observed at mid-latitudes. Ann Geophys 15:1037-1047.

Hosokawa K, Ogawa T, Yukimatu AS, Sato N, lyemori T. (2004) Statistics of Antarctic mesospheric echoes observed with the SuperDARN Syowa Radar. Geophys Res Lett 31:L02106. 
Karashtin, AN, Shlyugaev YV, Abramov VI, Belov IF, Berezin IV, Bychkov VV, Eryshev EB, Komrakov GP (1997) First HF radar measurements of summer mesopause echoes at SURA. Ann Geophys 15:935-941.

Kelley, MC, Huaman MM, Chen CY, Ramos C, Djuth F. Kennedy E (2002) Polar mesosphere summer echo observations at HF frequencies using the HAARP Gakona lonospheric Observatory. Geophys Res Lett 29(12):1603.

Latteck, R, Singer W, Höffner J (1999) Mesosphere summer echoes as observed by VHF radar at Külungsborn (54N). Geophys Res Lett 26(11):1533-1536.

Latteck R, Bremer J (2013) Long-term changes of polar mesospheric summer echoes at $69^{\circ}$ N. J Geophys Res Atmos 118:1-8.

Latteck R, Bremer J (2017) Long-term variations of polar mesospheric summer echoes at Andøya $\left(69^{\circ} \mathrm{N}\right)$. J Atmos Sol Terr Phys 163:31-37.

Li Q, Rapp M (2011) PMSE-observations with the EISCAT VHF and UHF-radars: Statistical properties. J Atmos Sol Terr Phys 73:944-956.

Morris RJ, Murphy DJ, Klekociuk AR, Holdsworth DA (2007) First complete season of PMSE observations above Davis, Antarctica, and their relation to winds and temperatures. Geophys Res Lett 34:L05805.

Morris RJ, Klekociuk AR, Latteck R, Singer W, Holdsworth DA, Murphy DJ (2009) Interhemispheric asymmetry in polar mesosphere summer echoes and temperature ay $69^{\circ}$ latitude. J Atmos Sol Terr Phys 71:464-469.

Nielsen K, Nedoluha GE, Chandran A, Chang LC, Barker-Tvedtnes J, Taylor MJ, Mitchell NJ, Lambert A, Schwartz MJ, Russell III JM (2011) On the origin of mid-latitude mesospheric clouds: The July 2009 cloud outbreak. J Atmos Sol Terr Phys 73:2118-2124.

Nishitani N, Ogawa T (2005) Model calculations of possible ionospheric backscatter echo area for a mid-latitude HF radar. Adv Polar Upper Atmos Res 19:55-62. 
Nishitani N, Ruohoniemi JM, Lester M, Baker JBH, Koustov AV, Shepherd SG, Chisham G, Hori T, Thomas EG, Makarevich RA, Marchaudon A, Ponomarenko P, Wild JA, Milan SE, Bristow WA, Devlin J, Miller E, Greenwald RA, Ogawa T, Kikuchi T (2019) Review of the accomplishments of Mid-latitude Super Dual Auroral Radar Network (SuperDARN) HF radars. Prog Earth Planet Sci 6:27.

Ogawa T, Nishitani N, Sato N, Yamagishi H, Yukimatu AS (2002) Upper mesosphere summer echoes detected with the Antarctic Syowa HF radar. Geophys Res Lett 29(7):1157.

Ogawa T, Nozawa S, Tsutsumi M, Arnold NF, Nishitani N, Sato N and Yukimatu AS (2004) Arctic and Antarctic polar mesosphere summer echoes observed with oblique incidence HF radars: analysis using simultaneous MF and VHF radar data. Ann Geophys 22:4049-4059.

Ogawa T, Nishitani N, Otsuka Y, Shiokawa K, Tsugawa T, Hosokawa K (2009) Medium-scale traveling ionospheric disturbances observed with the SuperDARN Hokkaido radar, all-sky imager, and GPS network and their relation to concurrent sporadic E irregularities. J Geophys Res 114:A03316.

Ogawa T, Kawamura S, Murayama Y (2011) Mesosphere summer echoes observed with VHF and MF radars at Wakkanai, Japan (45.4 N). J Atmos Sol Terr Phys 73:2132-2141.

Ogawa T, Nishitani N, Kawamura S, Murayama Y (2013) Mesosphere summer echoes observed with the SuperDARN Hokkaido HF radar at Rikubetsu, Japan $\left(43.5^{\circ} \mathrm{N}\right)$. Earth Planets Space 65:1593-1597.

Ramos C, Kelley MC, Djuth FT, Groves KM, Murayama Y, Kawamura S, Thorsen D (2009) Multifrequency observations of Polar Mesosphere Summer Echoes using Alaskan radar facilities: Comparisons and scattering calculations. Radio Sci 44:RS5011.

Rapp M, Gumbel J, Lübken FJ, Latteck (2002) D region electron number density limits for the existence of polar mesosphere summer echoes. J Geophys Res 107(D14):4187.

Rapp, M, Lübken FJ (2004) Polar mesosphere summer echoes (PMSE): review of observations 
and current understanding. Atmos Chem Phys 4:2601-2633.

Rauf A, Li H, Ullah S, Meng L, Wang B, Wang M (2018) Statistical study about the influence of particle precipitation on mesospheric summer echoes in polar latitudes during 2013. Earth Planets Space 70:108.

Reid, IM, Czechowsky P, Rüster R, Schmidt G (1989) First VHF radar measurements of mesopause summer echoes at mid-latitudes. Geophys Res Lett 16(2):135-138.

Russell III JM, Bailey SM, Gordley LL, Rusch DW, Horányi M, Hervig ME, Thomas GE, Randall CE, Siskind DE, Stevens MH, Summers ME, Taylor MJ, Englert CR, Espy PJ, McClintock WE, Merkel AW (2009) The aeronomy of Ice in the Mesosphere (AIM) mission:

Overview and early science results. J Atmos Sol Terr Phys 71:289-299.

Russell III JM, Rong P, Hervig ME, Siskind DE, Stevens MH, Bailey SM, Gumbel J (2014) Analysis of northern midlatitude noctilucent cloud occurrence using satellite data and modeling. J Geophys Res Atmos 119:3238-3250.

Singer W, Bremer J, Hocking WK, Weiss J, Latteck R, Zecha M (2003) Temperature and wind tides around the summer mesopause at middle and Arctic latitudes. Adv Space Res 31:2055-2060.

Smirnova M, Belova E, Kirkwood S, Mitchell N (2010) Polar mesosphere summer echoes with ESRAD, Kiruna, Sweden: Variations and trends over 1997-2008. J Atmos Sol Terr Phys 72:435-447.

Suzuki H, Sakanoi K, Nishitani N, Ogawa T, Ejiri MK, Kubota M, Kinoshita T, Murayama T, Fujiyoshi Y (2016) First imaging and identification of a noctilucent cloud from multiple sites in Hokkaido (43.2-44.4 $\mathrm{N})$, Japan. Earth Planets Space 68:182.

Taylor MJ, Gadsden M, Lowe RP, Zalcik MS, Brausch J (2002) Mesospheric cloud observations at unusually low latitudes. J Atmos Sol Terr Phys 64:991-999.

Thomas, L, Astin I, Prichard IT (1992) The characteristics of VHF echoes from the summer 
mesopause region at mid-latitudes. J Atmos Terr Phys 54:969-977.

Thomas L, Astin I (1994) The form of meter-scale turbulence at mesopause heights in summer. J Atmos Terr Phys 56:467-478.

Thomas L, Marsh AKP, Wareing DP, Astin I, Chandra H (1996) VHF echoes from the midlatitude mesosphere and the thermal structure observed by lidar. J Geophys Res 101(D8):12,867-12,877.

Thomas GE, Lumpe J, Bardeen C, Randall CE (2019) Albedo-Ice Regression method for determining ice water content of polar mesospheric clouds using ultraviolet observations from space. Atmos. Meas. Tech 12:1755-1766.

Wickwar VB, Taylor MJ, Herron JP (2002) Visual and lidar observations of noctilucent clouds above Logan, Utah, at 41.7ºN. J Geophys Res 107(D7):4054.

Williams PJS, Jones GOL, Palmer JR, Rishbeth H (1995) The association of polar mesosphere summer echo layers with tidal modes. Ann Geophys 13:454-457.

Zecha M, Bremer J, Latteck R, Singer W, Hoffman P (2003) Properties of midlatitude mesosphere summer echoes after three seasons of VHF radar observations at $54^{\circ} \mathrm{N}$. J Geophys Res 108(D8):8439.

Zeller O, Bremer J (2009) The influence geomagnetic activity on mesospheric summer echoes in middle and polar latitudes. Ann Geophys 27:831-837.

Zeller O, Hoffman P, Bremer J, Singer W (2009) Mesosphere summer echoes, temperature, and meridional wind variations at mid- and polar latitudes. J Atmos Sol Terr Phys 71:931942.

\section{Figures}




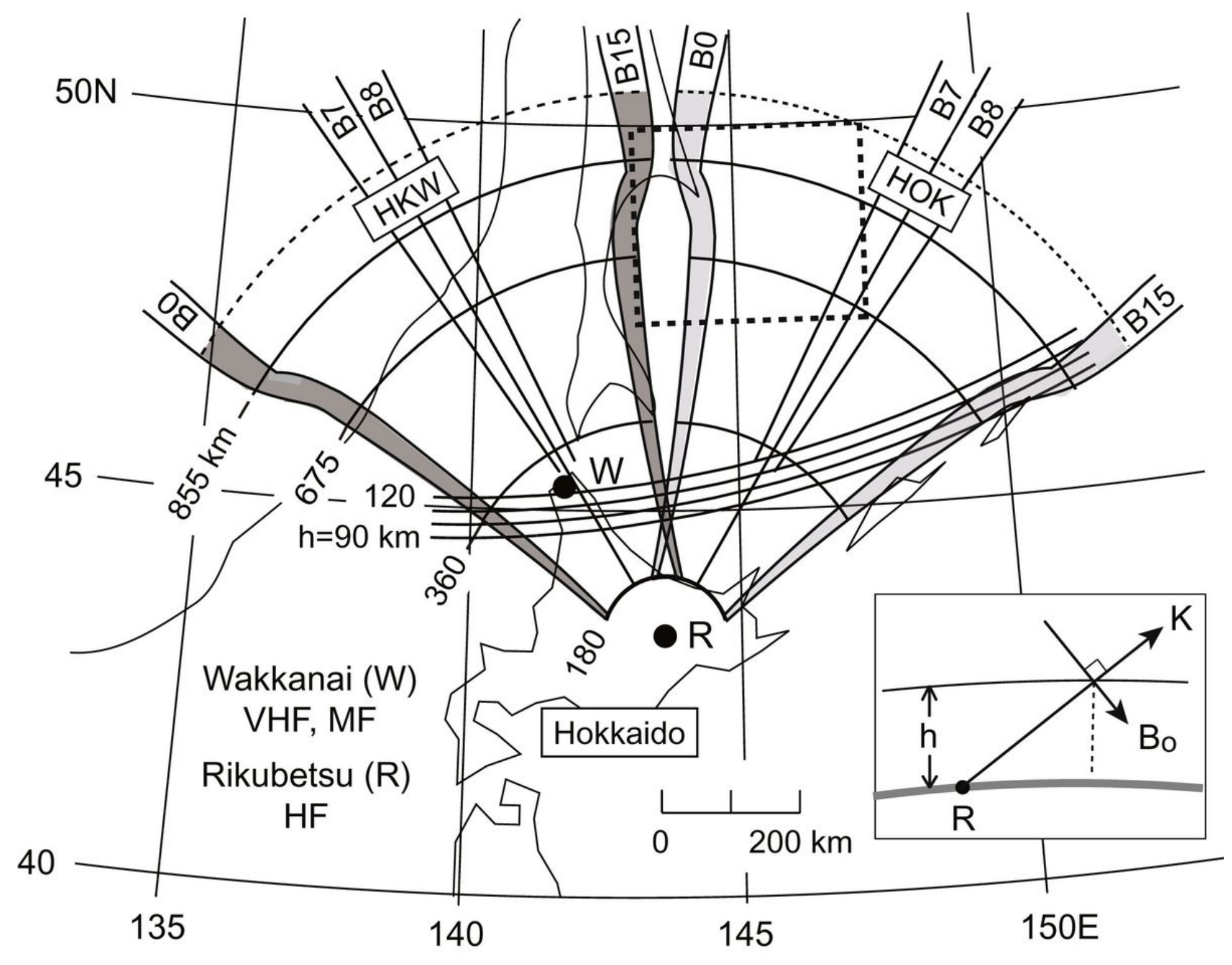

Figure 1

VHF and MF radars are collocated at Wakkanai (W) in Hokkaido. FOVs of two SuperDARN HF radars (HOK and HKW) at Rikubetsu (R), 260 km southeast of Wakkanai, are shown. Approximate slant ranges from the radar site $\mathrm{R}$ are indicated by the solid curves. Each HF radar has 16 narrow horizontal beams capable of detecting coherent echoes from the ionospheric E-region (90-120 km altitudes) as indicated in the figure. The NLC area photographed in Hokkaido on 21 July 2015 is indicated by the dotted rectangle (Suzuki et al. 2016). 


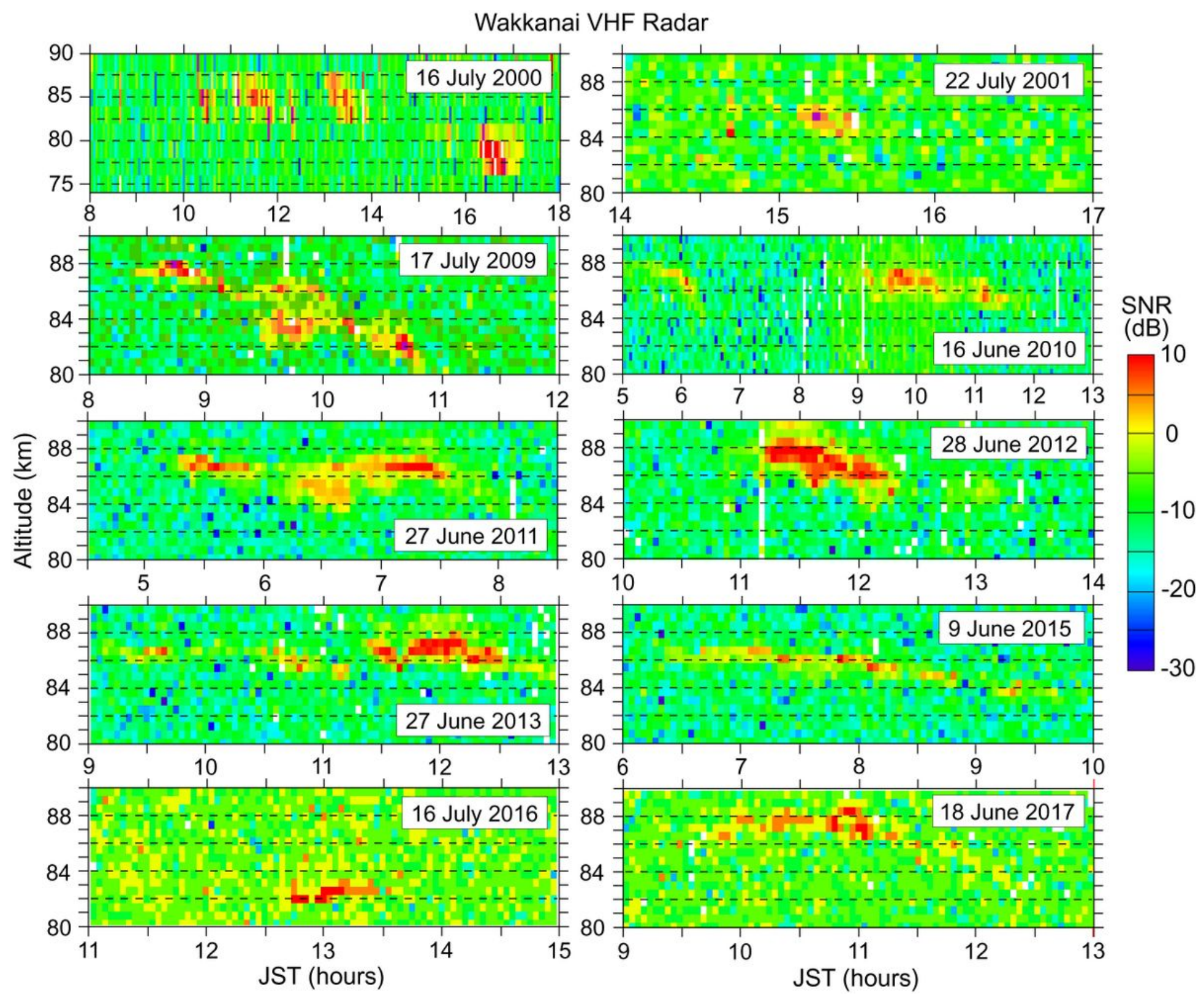

Figure 2

Examples of the altitude-time plot of VHF-SNR) observed in 2000-2001, 2009-2013 and 2015-2017. 
(a)

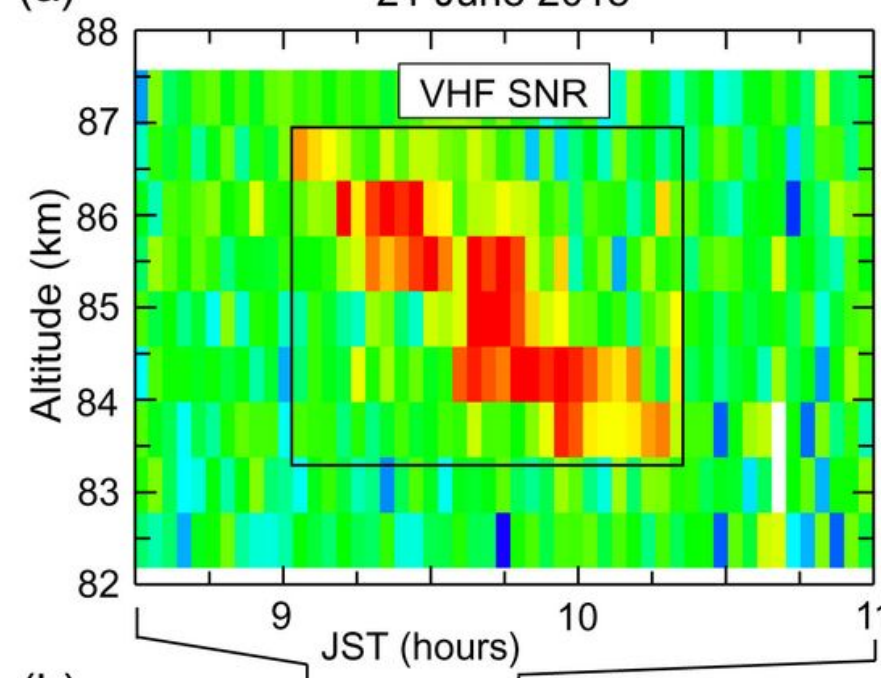

(b)

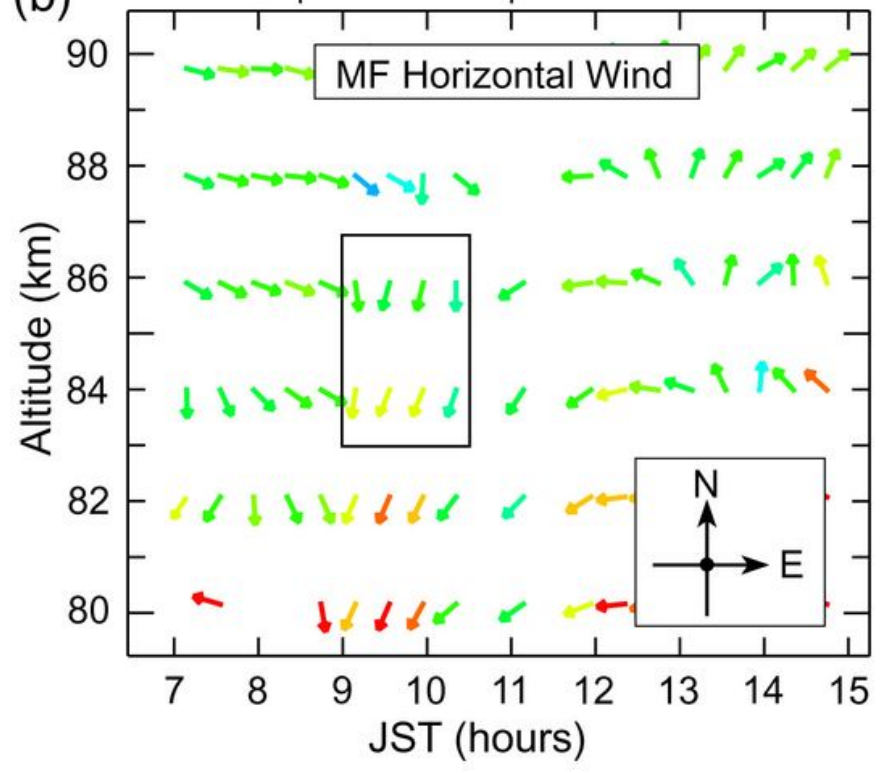

(c)

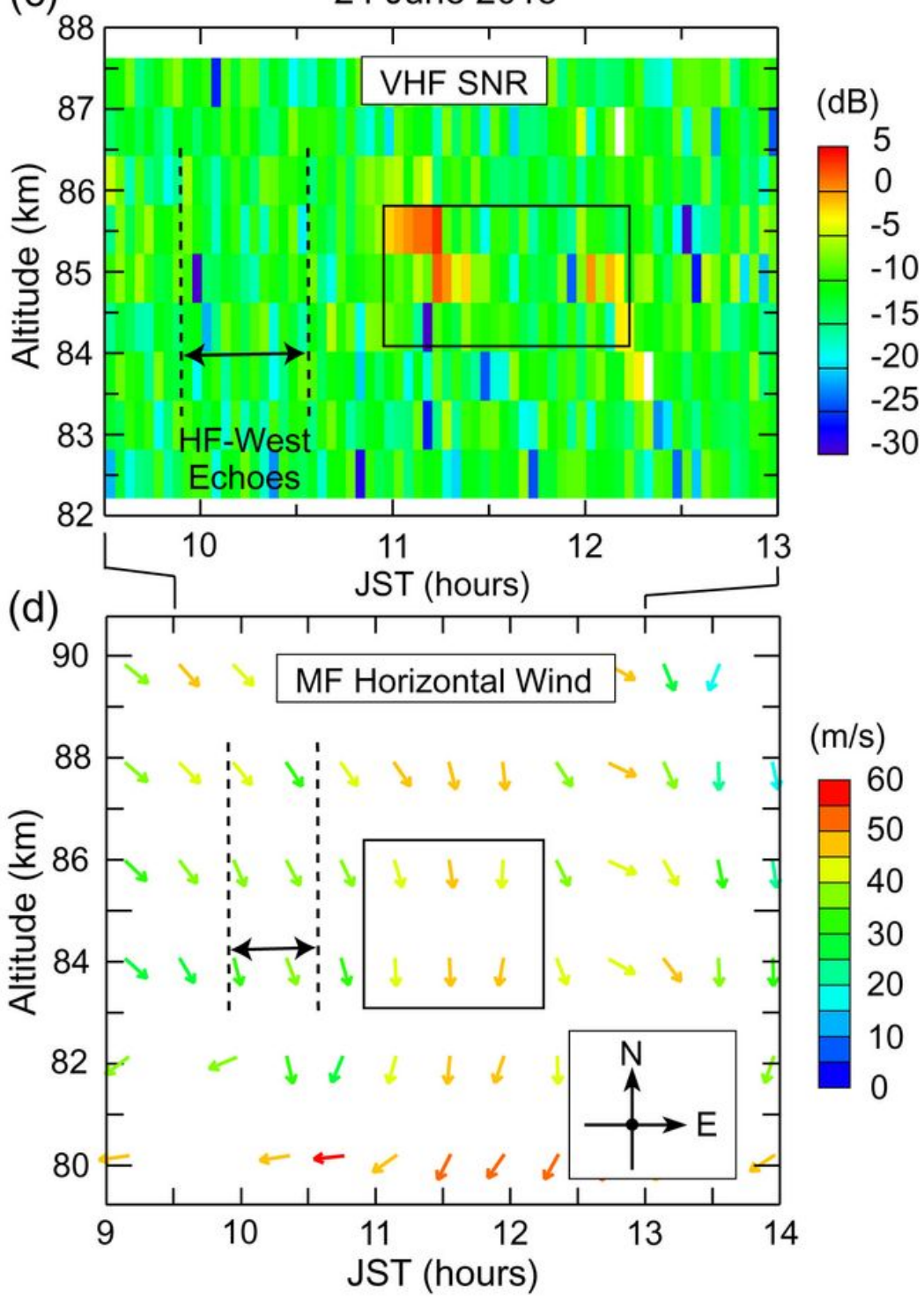

Figure 3

(a) Altitude-time plot of VHF-SNR and (b) MF horizontal wind vectors on 21 June 2015. In both figures, the MSE area is surrounded by the solid rectangle. (c) and (d) Same as Figs. 3a and 3b, respectively, but on 24 June 2015. In both figures, the time-interval of strong echoes observed with the West HF radar (HKW) is indicated by the broken lines. 


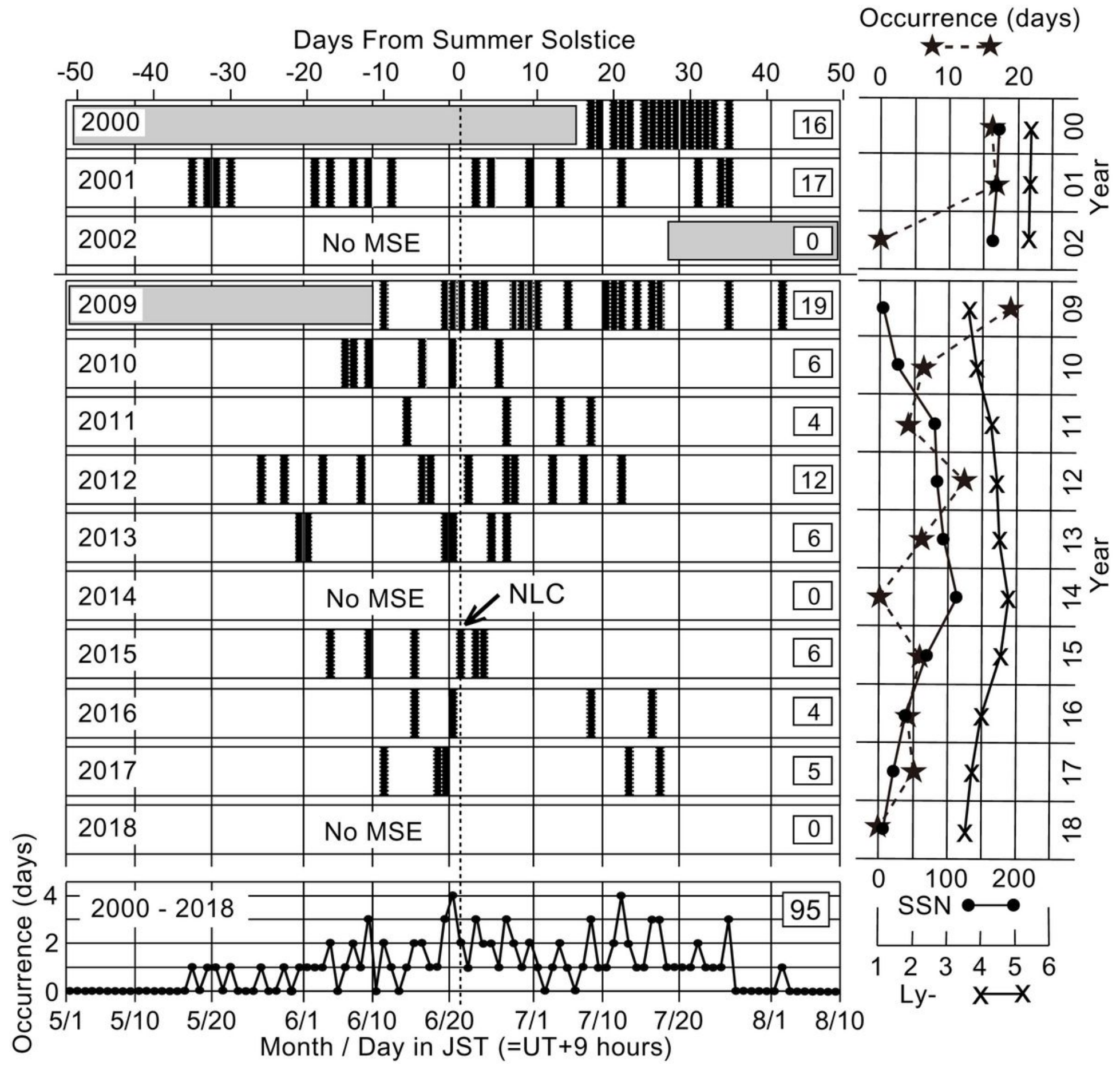

Figure 4

(Left) VHF-MSE occurrence days (vertical black bars) for 13 years. No observation periods are indicated by the gray rectangles. Daily variation of total MSE occurrence days for 13 years is shown in the bottom. MSE were not observed in 2000, 2014 and 2018. NLC were observed in the north of Hokkaido on 21 June 2015. (Right) Variations of yearly MSE occurrence days, yearly sunspot number (SSN) and Ly-a (1011 photons/cm2/sec). 

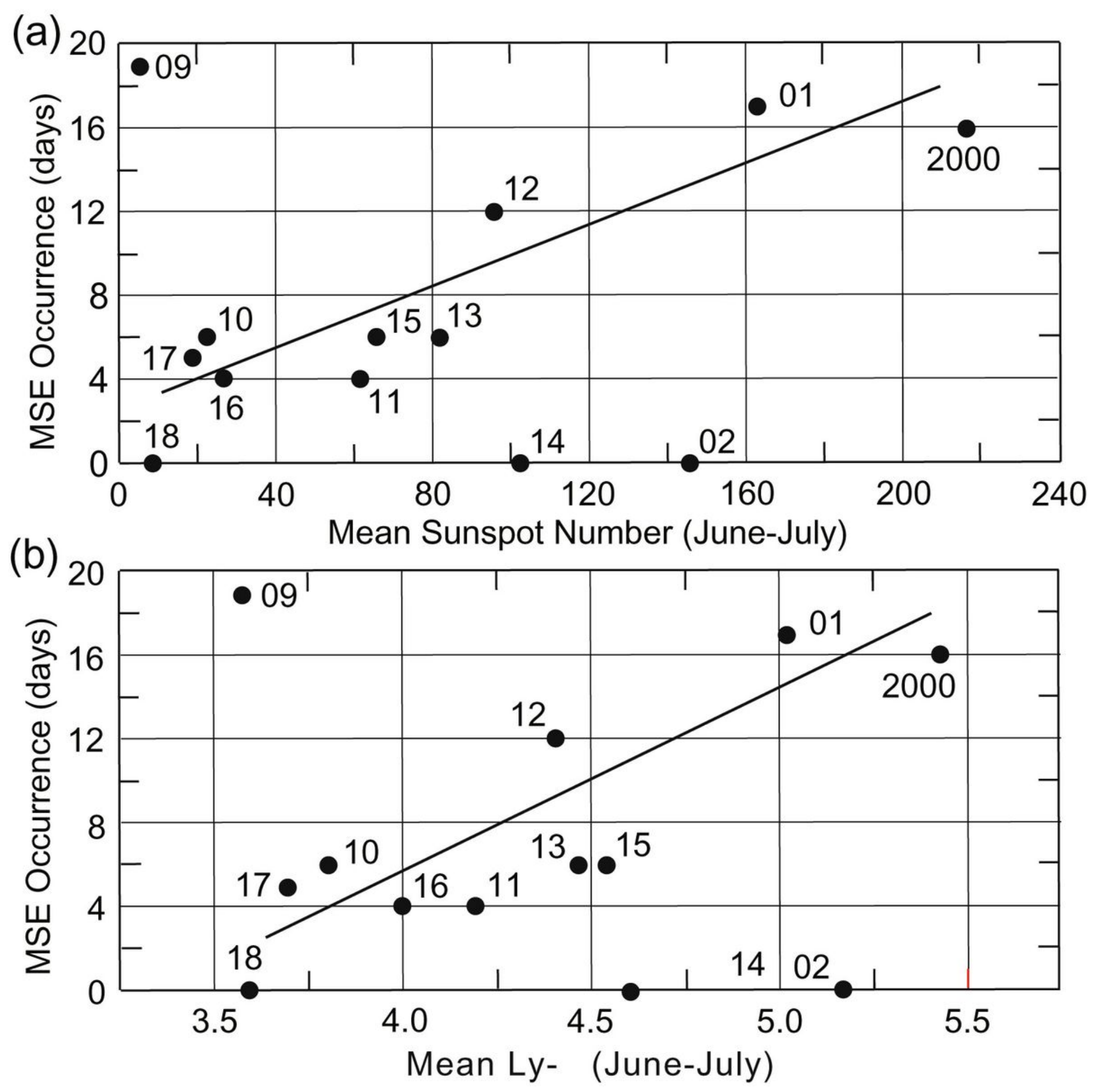

Figure 5

Dependence of yearly MSE occurrence days on (a) sunspot number (mean during June-July) and (b) Ly-a (mean during June-July) for 13 years (2000-2002 and 2009-2018). 


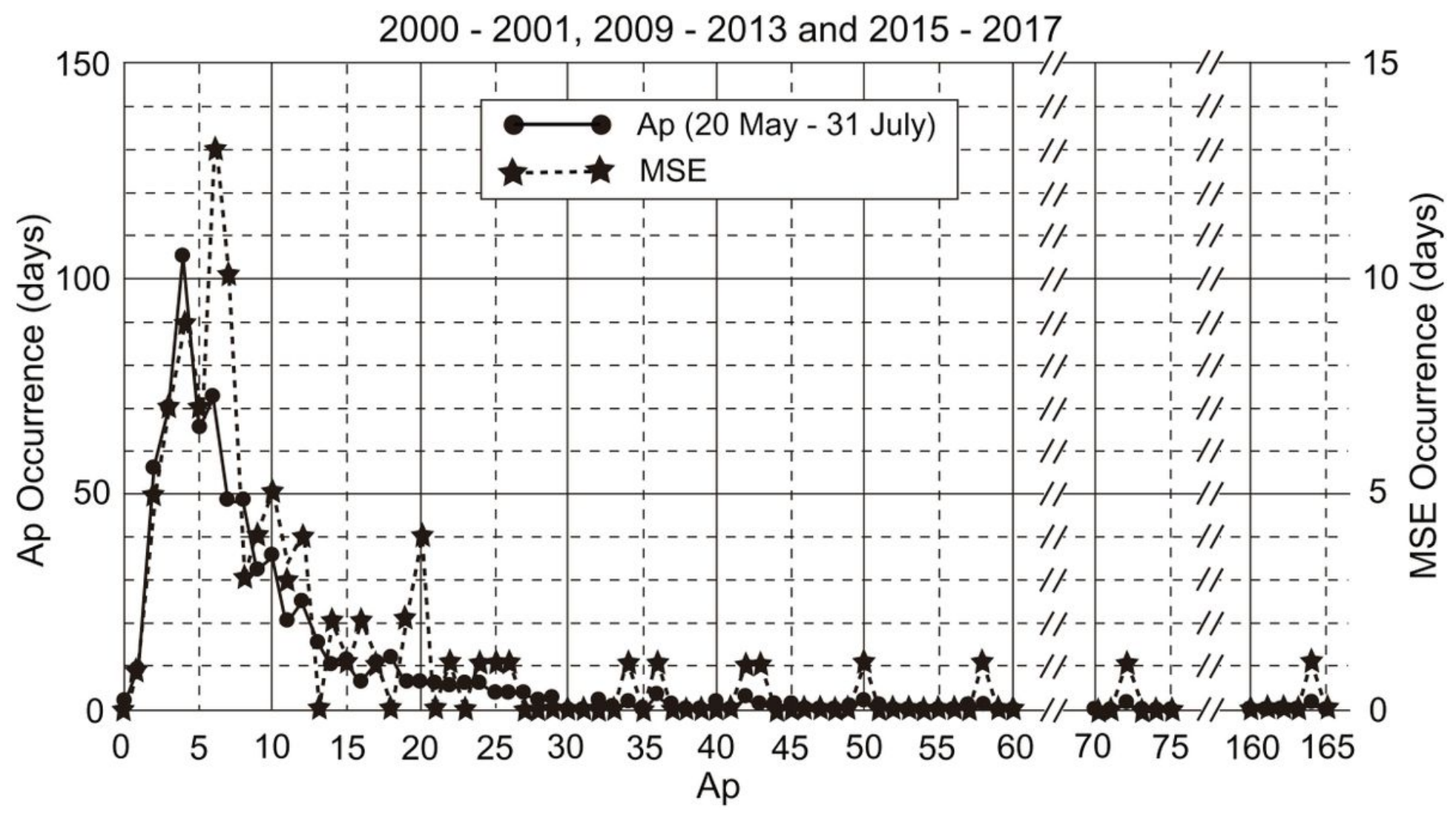

Figure 6

Dependence of Ap occurrence days (total during 20 May - 31 July: solid lines) and MSE occurrence days (dotted lines) on Ap index for 10 years (2000-2001, 2009-2013 and 2015-2017). 


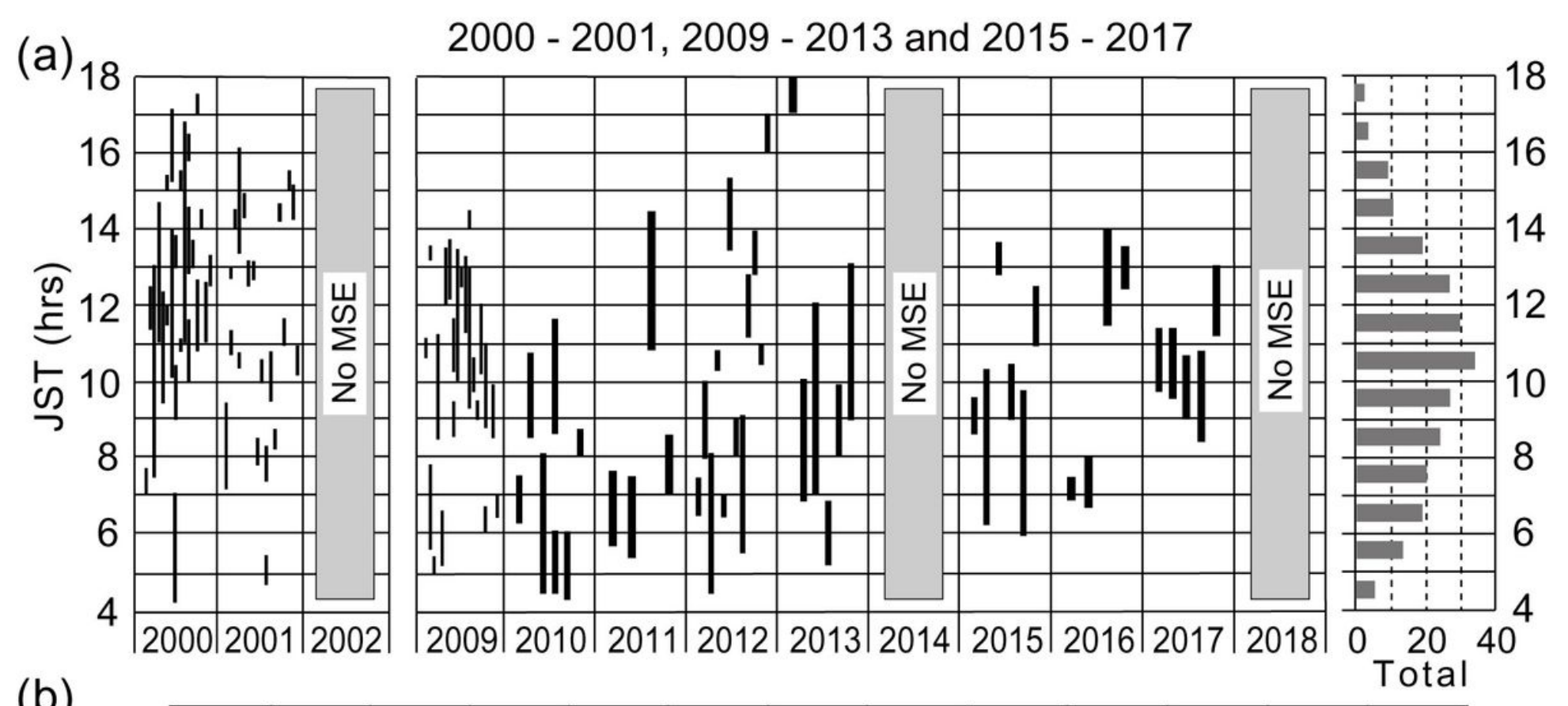

(b)

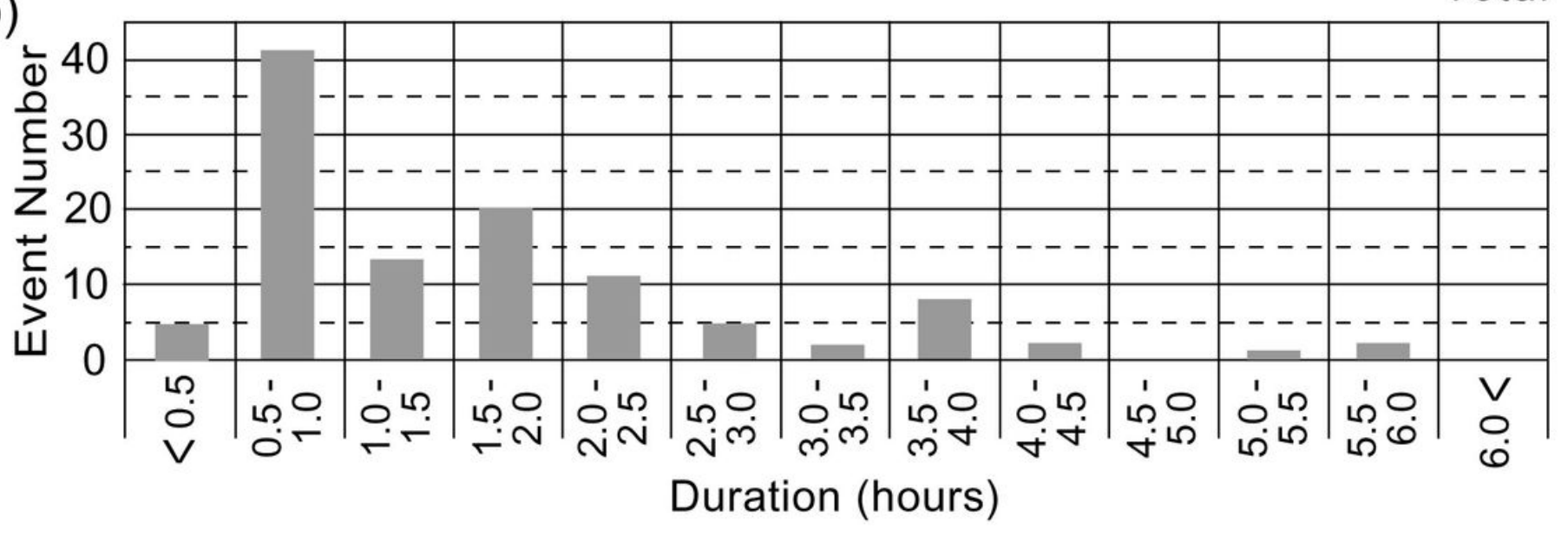

Figure 7

(a) Time extent of each MSE event in each year (110 events in total) and histogram of total occurrence number for 10 years (2000-2001, 2009-2013 and 2015-2017). (b) Histogram of total event number of MSE duration for ten years. 

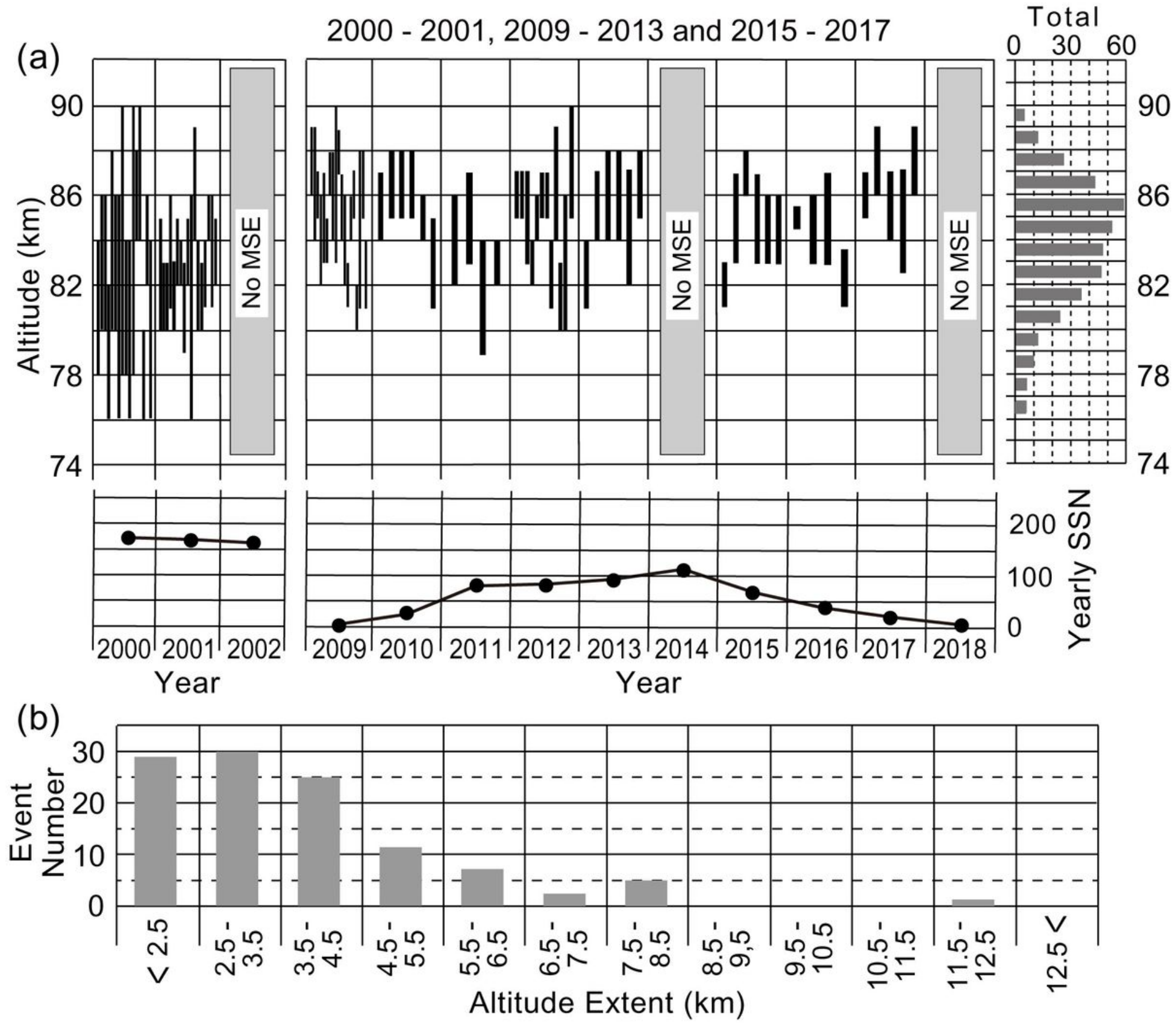

Figure 8

(a) Altitude extent of each MSE event in each year (110 events in total), histogram of total occurrence number for 10 years (2000-2001, 2009-2013 and 2015-2017), and variation of yearly SSN for 13 years. (b) Histogram of total event number of MSE altitude extent for 10 years. 
(a) Days From Summer Solstice

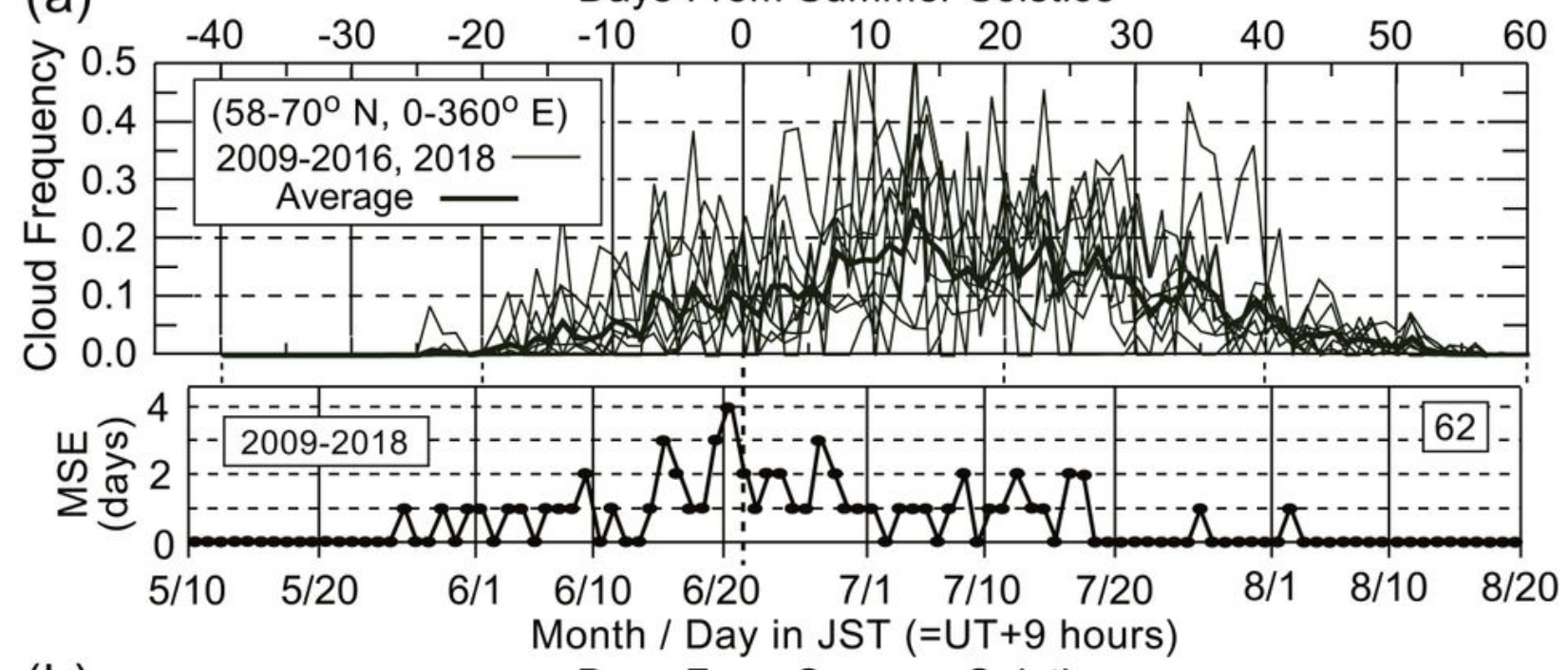

(b) Days From Summer Solstice

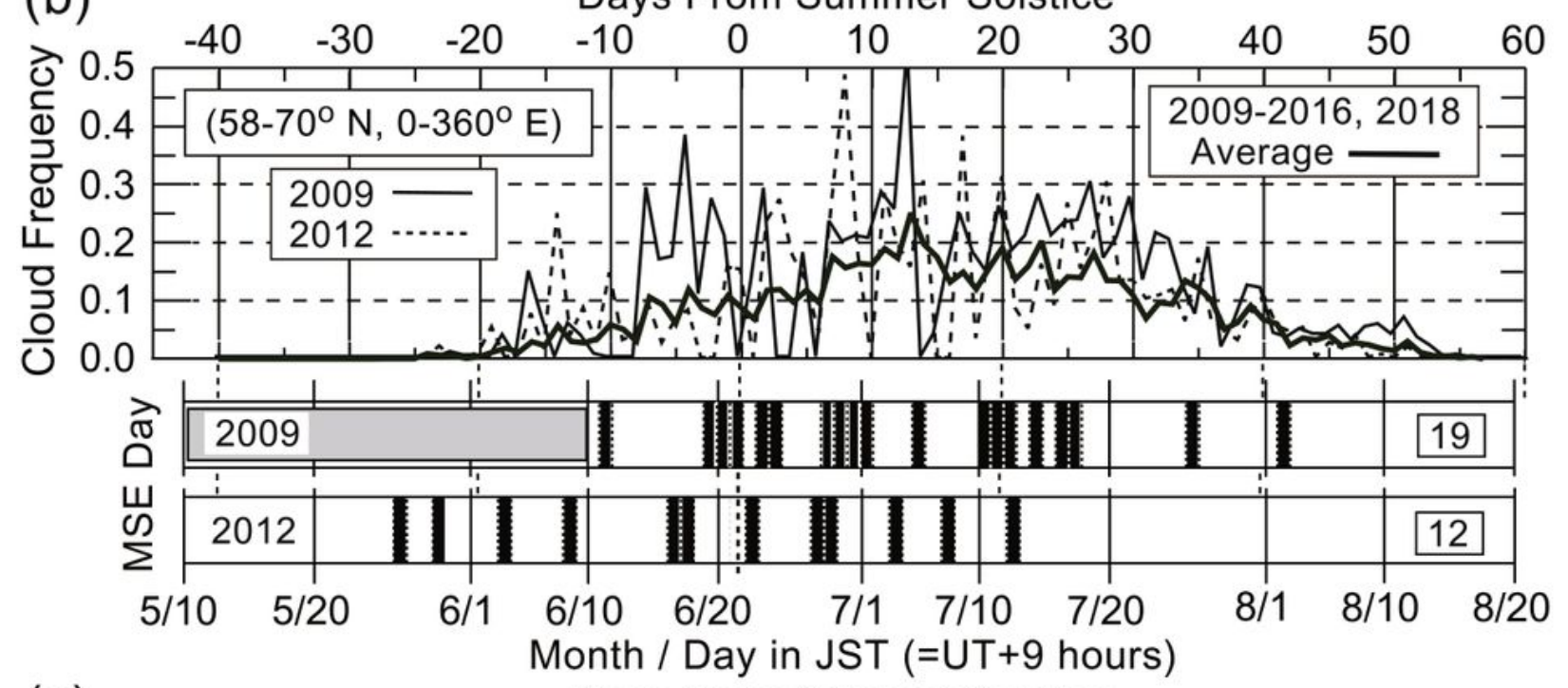

(c)

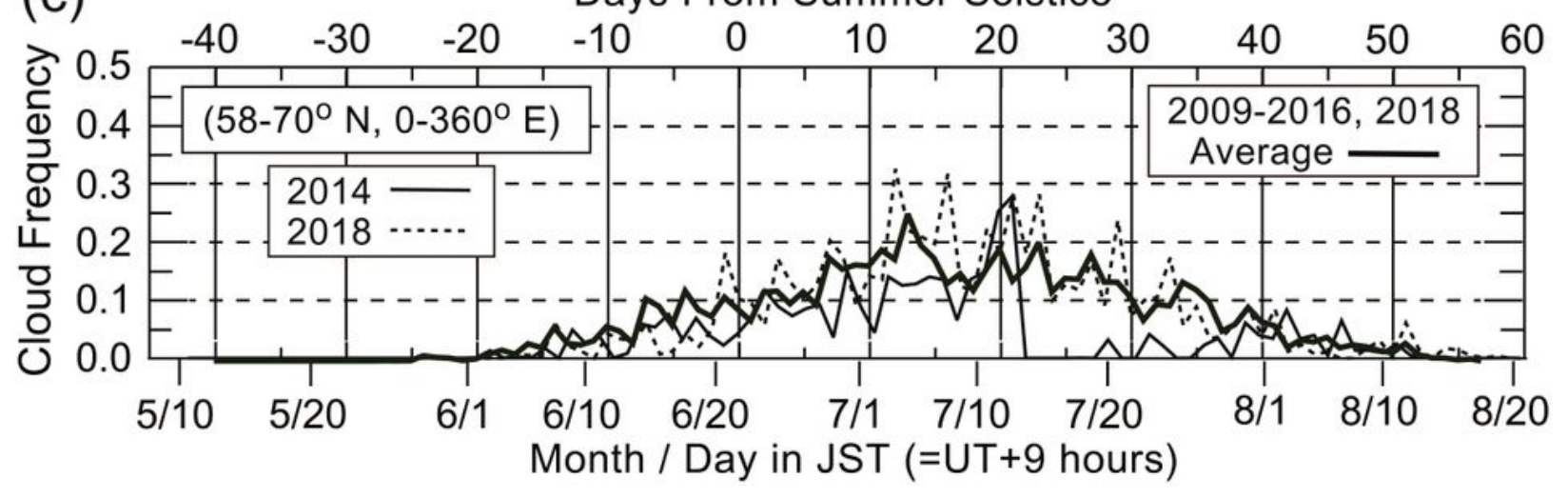

Figure 9

(a) Daily variations of AIM-CIPS cloud frequency (CF), averaged over both $58-70^{\circ} \mathrm{N}$ and $0-360^{\circ} \mathrm{E}$, in each year during 2009-2016 and in 2018. CFs averaged over 9 years are indicated by the thick line. The lower panel shows the daily variation of MSE occurrence days (62 days in total) during 2009-2018. (b) Daily variations of CFs in 2009 and 2012, and 9-year average CFs. The lower panels show the MSE occurrence 
days (vertical black bars) in 2009 and 2012. (c) Daily variations of CFs in 2014 and 2018, and 9-year average CFs.

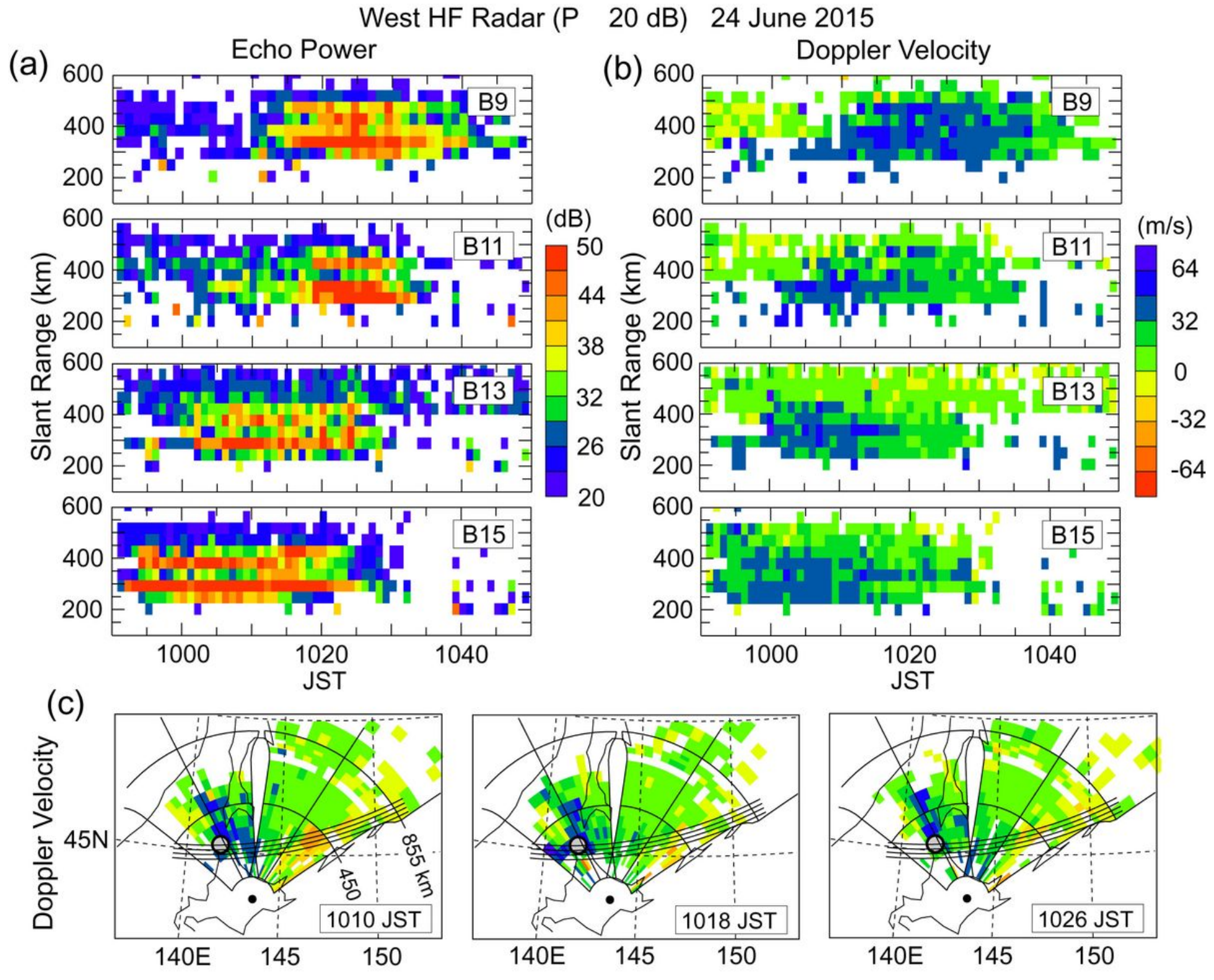

West HF Radar (P 20 dB) 24 June 2015

Figure 10

(a) Range-time plot of echo power ( $\geq 20 \mathrm{~dB}$ ) on beams $9,11,13$ and 15 observed with the West HF radar (HKW) on 24 June 2015. (b) Range-time plot of Doppler velocity. (c) Doppler velocity maps at three times.

\section{Supplementary Files}

This is a list of supplementary files associated with this preprint. Click to download.

- GraphicalAbst.png 